\title{
Circuito de quatro estações aplicando a computação desplugada
}

\author{
Luciana P. de Araújo Kohler, Mauro M. Mattos, Fabrícia D. Zucco, Heitor Ugarte, \\ Leonardo Fronza, Gian C. Giovanella, Bruno F. F. Santos, Jorge Kohn \\ ${ }^{1}$ Laboratório de Desenvolvimento e Transferência de Tecnologias (LDTT) \\ Universidade Regional de Blumenau (FURB) \\ Blumenau - SC - Brasil. \\ \{mattos, lpa, hucsilveira, leofronza, bffsantos\}@furb.br \\ \{gcgiovanella, rwessling, fabricia, wuo, jgtridapalli\}@furb.br
}

\begin{abstract}
With purpose to introduce the computational thinking in the elementary school, the extension project developed a circuit with four stations containing activities related to computational thinking. As some schools do not have informatic lab until the application of the circuit, it was decided working with the unplugged computing. The circuit was applied in five classes of two different schools. After all ludic activities, it is understand that the children was developed some abilities of computational thinking.
\end{abstract}

Resumo. Com o objetivo de introduzir o pensamento computacional no ensino fundamental, o projeto de extensão criou um circuito com quatro estações contendo atividades relacionadas ao pensamento computacional. Como algumas escolas não possuíam laboratório até o momento da aplicação do circuito, decidiu-se trabalhar com a computação desplugada. O circuito foi aplicado em cinco turmas de duas escolas diferentes. Após todas as atividades lúdicas realizadas, percebeu-se que as crianças conseguiram desenvolver algumas das habilidades do pensamento computacional.

\section{Introdução}

O termo Pensamento Computacional (PC), introduzido em [Wing 2006], e um metodo para ensinar a solucionar problemas, conceber sistemas e compreender o comportamento humano inspirando-se em conceitos da Ciência da Computação ou, como colocado por [de Paula et al. 2014], "e uma maneira específica de se pensar e de analisar uma situação ou um artefato, sendo independente do uso da tecnologia". Assim, desenvolver habilidades em PC não significa necessariamente aprender a programar [Zanetti et al. 2016].

As tres habilidades basicas que fundamentam o PC sao: abstracao, automacao e analise. A habilidade de abstracao esta associada a capacidade de o individuo extrair apenas as caracteristicas mais importantes de um problema para chegar a uma solucao. A habilidade de automacao está associada a capacidade de utilizacao de algum meio eletronico que pode substituir o trabalho de um ser humano e a habilidade de analise esta associada ao estudo dos resultados gerados pela automacão [Zanetti et al. 2013].

Nesse contexto também se encontra a computação desplugada. A computação desplugada é um método educacional para ensinar conceitos de computação sem o uso 
VIII Congresso Brasileiro de Informática na Educação (CBIE 2019)

Anais do XXV Workshop de Informática na Escola (WIE 2019)

de computadores e/ou tecnologias e normalmente é utilizado para ensinar pessoas que não são especialistas em computação, sendo bem aplicado no âmbito infantil e escolar [Nishida et al. 2009].

Nesse sentido, este relato de experiência refere-se a uma atividade realizada em um projeto de extensão que tem como objetivo introduzir o pensamento computacional nos anos inicias ( $1^{\circ}$ ao $5^{\circ}$ ano do ensino fundamental) em escolas públicas do município. Para introduzir conceitos de pensamento computacional, propôs-se uma atividade com quatro estações utilizando diferentes práticas de computação desplugada as quais são relatadas a seguir.

\section{Metodologia e Circuitos}

Com o objetivo de introduzir questões do pensamento computacional sem o uso do computador, criou-se um circuito com quatro estações contendo atividades relacionadas as habilidades do pensamento computacional. Para a concepção das atividades, utilizou-se como base as definições curriculares do Centro de Inovação para a Educação Brasileira (CIEB) [CIEB 2018]. Para metodologias de aplicação e inspiração das atividades utilizouse o trabalho de [Guarda et al. 2018] que realizou um circuito com 4 desafios para turma de ensino fundamental, focado na área de problemas matemáticos.

A atividade foi realizada com cinco turmas diferentes do ensino fundamental, sendo as turmas do $1^{\circ}$ ao $5^{\circ}$ ano. A atividade ocorreu durante 1 hora e 30 minutos com cada uma das turmas, durante seu período letivo de aula, de modo que todos os alunos das turmas participaram da atividade. As turmas eram compostas por uma média de 20 alunos, de modo que em cada estação do circuito trabalhavam cerca de 5 alunos de forma simultânea. Cada estação teve duração aproximada de 20 minutos. Os 30 minutos restantes foram utilizados para troca de uma estação para outra e para uma reflexão ao final da atividade.

As atividades foram alocadas em três espaços diferentes sendo duas salas de aula e um pátio. Dessa forma, as crianças puderam se acomodar bem em cada uma das estações, sem que uma atividade atrapalhasse a outra. Em cada estação ficaram 2 monitores para controlar as atividades, tirar dúvidas e realizar as anotações referentes ao aprendizado da atividade em relação ao Pensamento Computacional. Antes de iniciar a atividade, as estações foram explicadas para todos os participantes, contudo, sempre ao iniciar a estação a atividade era relembrada para orientar os participantes.

Dessa forma, as quatro atividades foram: jogo de tabuleiro com cartas; jogo de tabuleiro vivo; identificação de bug; e ordenação de cartas.

O jogo tabuleiro com cartas representado na Figura 1 (A) tem por objetivo fazer com que o jogador saia de uma origem e chegue até um destino do tabuleiro utilizando de cartas que indicam comandos de movimentação no mapa, sendo: andarNorte ( ) ; , andarSul () ; , andarLeste () ;, e andarOeste ();. Ao concluir o objetivo, o jogador tem a sequência de cartas que utilizou para sair da origem e chegar ao destino. Esta sequência é a representação de um código-fonte. Assim, realizando este processo, o aluno é introduzido a alguns conceitos do pensamento computacional, como: sequência de instruções (as cartas utilizadas devem ser lidas em uma sequência); algoritmo (a junção das cartas formam um algoritmo a ser interpretado e executado quantas vezes forem 
VIII Congresso Brasileiro de Informática na Educação (CBIE 2019)

Anais do XXV Workshop de Informática na Escola (WIE 2019)

necessárias); identificação de que o computador só realiza o que foi executado, isto é, o peão só poderá se movimentar se foi indicado o comando a partir da carta para ele.

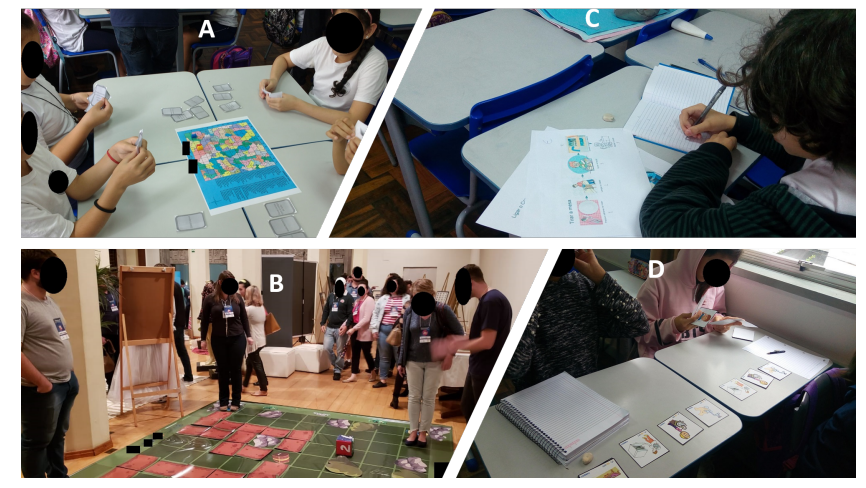

Figura 1. Atividades desplugadas.

O jogo de tabuleiro vivo é semelhante ao jogo de tabuleiro com cartas e é representado na Figura 1 B. Ele é constituído de um tabuleiro grande com linhas e colunas, sendo que os peões são representados pelos próprios jogadores. Cada jogador representa um personagem e possui um determinado objetivo. Os jogadores das bordas são denominados de Furbot e o jogador do centro é denominado de Alien. O objetivo dos Furbots é chegar até o tesouro e o objetivo do Alien é pegar o Furbot. Caso o Alien toque em um Furbot, este vira também um Alien e ajuda a pegar os outros Furbots. Caso um Furbot chegue no centro do mapa, ele vira um Anjo e então sua missão é salvar um Alien. Após salvar o Alien, o jogador Anjo e o Alien salvo voltam a ser Furbots. O jogo finaliza quando todos são Aliens ou todos são Furbots. Para se movimentar pelo cenário, na sua vez, o jogador deve jogar um dado e andar pelo tabuleiro a quantidade de passos correspondentes ao valor do dado, não podendo se movimentar nas diagonais. Além das habilidades de pensamento computacional que envolviam a atividade, a criança é estimulada a criar estratégias de jogo e a pensar antes de agir, pois com base em seus movimentos ela poderá ganhar ou perder o jogo.

A atividade de identificação de bugs representada na Figura $1 \mathrm{D}$ é jogada individualmente. Nesse caso, o aluno recebe cinco folhas contendo cada uma a sequência de passos de uma atividade cotidiana, sendo elas: dormir; ir para a aula; ligar o computador; comer; e tomar banho. Acontece que, na sequência apresentada há passos que estão trocados. Dessa forma, o aluno deve identificar as inconsistências apresentadas nessas sequências, ou seja, os bugs.

A quarta atividade de sequência de cartas representada na Figura $1 \mathrm{D}$ também é jogada individualmente. Cada jogador recebe um monte com uma quantidade de cartas e deve ordena-las, sendo que elas ordenadas representam alguma ação do cotidiano, como: colocar a louça na mesa, comer e lavar a louça; e, tomar banho e se vestir. Dessa forma, a atividade também trabalha questões do pensamento computacional como a sequência de passos e a composição de passos em um problema (que seria o inverso da decomposição).

\section{Resultados e Discussões}

As quatro atividades foram projetadas para serem aplicadas igualmente nas cinco turmas do ensino fundamental, sendo que foi possível a realização da mesma. 
VIII Congresso Brasileiro de Informática na Educação (CBIE 2019)

Anais do XXV Workshop de Informática na Escola (WIE 2019)

Com relação a primeira atividade do jogo de tabuleiro, no tempo da atividade cada equipe conseguiu jogar de duas a três vezes. Observou-se que a medida em que as rodadas iam avançados, as crianças tomavam mais conhecimento a respeito das regras do jogo e a medida em que as movimentações eram realizadas, elas tomadas decisões mais sábias ao utilizar suas cartas. Por exemplo, no princípio acontecia da criança jogar a carta andarNorte () ; e na mesma rodada a carta andarSul () ;. Jogando essas duas cartas o seu peão ficaria na mesma posição, contudo a criança jogava a carta para eliminar cartas de sua mão. Ainda, elas foram instruídas que quanto menor a quantidade de cartas, mais eficiente será seu código-fonte final produzido. Assim, elas passaram a pensar antes de utilizar uma carta ou de troca-la com o monte.

Ao finalizar o jogo, o monitor da atividade verificava se as cartas jogadas estavam corretas de acordo com o caminho que foi percorrido. A maioria das crianças observavam a execução na primeira vez e ao terminarem um segundo jogo executavam esses passos sozinhas, conferindo umas das outras se o peão tinha se movimentado de acordo com as cartas utilizadas. Com isso praticou-se a lógica sequencial, a decomposição do problema em partes (sendo elas as cartas) e a codificação do algoritmo.

Em relação a segunda atividade do tabuleiro humano, percebeu-se ser uma atividade mais lúdica. Nesta atividade as crianças se divertiam mais, contudo, também aprendiam sem perceber. As crianças treinaram principalmente a tomada de decisão e o planejamento estratégico para então tomar a ação. Também incentivou-se o trabalho em equipe, uma vez que se iniciavam com quatro Furbots que tinham que fugir do Alien e alcançar o tesouro.

A terceira atividade da identificação dos bugs treinou também habilidades de abstração e decomposição de problemas, além do reconhecimento de padrões, sendo estes vindos do mundo real aplicados por meio da sequência. Essa atividade foi um pouco mais difícil para as crianças sendo que nem todas conseguiram completar as cinco questões corretamente. A maioria dos erros cometidos foram por falta de atenção, pois, ao serem questionadas pelo monitor do motivo da resposta, logo elas percebiam que estava incorreta e se justificavam corrigindo o problema. Isso pode ter ocorrido pelo fato de que nesta atividade o problema é apresentado como um todo e o aluno deve extrair as informações mentalmente para então coloca-la em uma ordem lógica novamente.

Por fim, a quarta atividade da ordenação das cartas de forma geral foi simples para as crianças, até mesmo para as crianças de primeiro ano. Houve poucos erros de lógica na construção das sequências e, ainda, a maioria dos erros cometidos eram por interpretação errônea da carta. Percebeu-se que após a explicação, elas conseguiam compreender o que fazer na atividade. Algumas crianças demoraram mais tempo do que outras para chegar a solução lógica, contudo, todas conseguiram. Essa atividade estimulou o raciocínio lógico e a construção de uma sequência cotidiana podendo ser representada posteriormente por um algoritmo. Também foi trabalhada a abstração, uma vez que as cartas representavam situações cotidianas através de uma única imagem.

Ao final do circuito, ainda houve um tempo de debate com cada turma para que as crianças percebessem algumas das habilidades praticadas. O que chamou a atenção, é que várias crianças destacaram que aprenderam que é necessário pensar antes de agir, a pensar para tomar decisões e ainda que é importante trabalhar em equipe. Embora elas 
VIII Congresso Brasileiro de Informática na Educação (CBIE 2019)

Anais do XXV Workshop de Informática na Escola (WIE 2019)

não tenham a percepção clara dos fatores do pensamento computacional, estes fatores auxiliaram para que elas pudessem levar lições para o seu dia a dia.

\section{Considerações Finais}

O projeto de extensão tem como objetivo introduzir o pensamento computacional nas escolas de ensino fundamental da região. Para isso, realizou-se como atividade introdutória um circuito com quatro estações sendo estas relatadas no artigo.

Percebeu-se que com a atividade em forma de circuitos, pode-se trabalhar de formas diferenciadas habilidades do pensamento computacional sendo a a abstração, algoritmos, decomposição e reconhecimento de padrões. Ainda, em uma forma lúdica, as crianças foram introduzidas a estes conceitos sem ter a noção exata do que eles significam, mas sim, vivenciando-os na prática a partir de cada estação.

Dessa forma, entende-se que a atividade das quatro estações em forma de um circuito estimulou as crianças a participarem e introduziu algumas das habilidades do pensamento computacional que podem ser trabalhadas de outras formas posteriormente. Ainda, a computação desplugada permite que as habilidades sejam praticadas em qualquer espaço de qualquer escola, sem que ela tenha um laboratório de informática, permitindo uma ampliação na divulgação do conhecimento destas habilidades.

Logo, pretende-se aplicar a dinâmica em outros grupos de crianças, além de disponibilizar essas atividades para que qualquer escola ou grupo possa utilizar e aplicar em seu ambiente.

\section{Referências}

CIEB (2018). Currículo de referência em tecnologia e computação. http:// curriculo.cieb.net.br/curriculo.

de Paula, B. H., Valente, J. A., e Burn, A. (2014). O uso de jogos digitais para o desenvolvimento do currículo para a educação computacional na inglaterra. Currículo sem Fronteiras, 14(3):46-71.

Guarda, G., Gonçalves, C. D. S., Cunha, L. R. R., e Goulart, I. (2018). O circuito quatro desafios: Atividade lúdica apoiada pelo pensamento computacional. In Anais dos Workshops do VII Congresso Brasileiro de Informática na Educação (CBIE 2018). Brazilian Computer Society (Sociedade Brasileira de Computação - SBC).

Nishida, T., Kanemune, S., Idosaka, Y., Namiki, M., Bell, T., e Kuno, Y. (2009). A cs unplugged design pattern. SIGCSE Bull., 41(1):231-235.

Wing, J. M. (2006). Computational thinking. Commun. ACM, 49(3):33-35.

Zanetti, H., Borges, M., e Ricarte, I. (2013). Proposta de atividades para o desenvolvimento do pensamento computacional no ensino fundamental. In Anais do XXVII Simpósio Brasileiro de Informática na Educação (SBIE 2013). Sociedade Brasileira de Computação - SBC.

Zanetti, H., Borges, M., e Ricarte, I. (2016). Pensamento computacional no ensino de programação: Uma revisão sistemática da literatura brasileira. In Anais do XXVII Simpósio Brasileiro de Informática na Educação (SBIE 2016). Sociedade Brasileira de Computação - SBC. 